\title{
Effect of Mortar Age on the Textile-to-Mortar Bond Behavior
}

\author{
Ali Dalalbashi ${ }^{1}$, Bahman Ghiassi $^{2}$, and Daniel V. Oliveira ${ }^{3}$ \\ ${ }^{1} \mathrm{PhD}$ Student, ISISE, University of Minho, Department of Civil Engineering, Azurém, 4800-058 \\ Guimarães, Portugal. E-mail: alidalalbashi@gmail.com \\ ${ }^{2}$ Assistant Professor, Centre for Structural Engineering and Informatics, Faculty of Engineering, \\ University of Nottingham, Nottingham, United Kingdom. E-mail: bahman.ghiassi@nottingham.ac.uk \\ ${ }^{3}$ Associate Professor, ISISE \& IB-S, University of Minho, Department of Civil Engineering, Azurém, \\ 4800-058 Guimarães, Portugal. E-mail: danvco@civil.uminho.pt
}

\begin{abstract}
Textile-reinforced mortar (TRM) composites have received extensive attention as a sustainable solution for seismic strengthening of masonry and historical structures. This new system is composed of textile fibers embedded in an inorganic matrix and is applied on the masonry and the concrete substrate surface as an externally bonded reinforcement (EBR) system. The bond at the textile-to-mortar interfaces is the main stress-transfer mechanism and, therefore, should be thoroughly investigated. Furthermore, the effectiveness of TRMs in improving the seismic performance of existing structures is highly dependent on the durability of its components, materials, textile-to-mortar bond, and their long-term behavior. Due to the novelty of these materials in application to masonry structures, several aspects related to the durability and long-term performance of them are still not clear. To that end, a new study has been launched that looks at the time effect on the mechanical properties and bond behavior between fiber and mortar. For this purpose, two different hydraulic lime-based mortars, as well as steel and glass fibers, are used to investigate the effect of mortar age on the TRM system after 180 days. The results show that at the early age of mortars, their mechanical properties, and the bond behavior of textile-to-mortar have been increased. Another critical point to remember is that by increasing the mortar age, textile-to-mortar bond and mortar strength are decreased.
\end{abstract}

Keywords: Textile-to-Mortar Bond Behavior, Durability, Long-Term Behavior, Degradation Mechanism.

\section{Introduction}

The advantages of textile reinforced mortar (TRM) composites to fiber-reinforced polymers (FRPs) are the fire resistance, the vapor permeability, the removability, and the compatibility with masonry and concrete substrates (Carozzi and Poggi, 2015; Papanicolaou, Triantafillou, Papathanasiou, and Karlos, 2007). Thus, these advantages have made TRM composites very interesting for externally bonded reinforcement of masonry and reinforced concrete structures.

Mechanical properties of the TRMs and structural components strengthened with TRMs are strongly dependent on the properties of both the mortar and the fiber, the interfacial bond behavior of the fiber-to-mortar, and the interfacial bond behavior between the TRM composite and masonry substrate (Ghiassi, Oliveira, Marques, Soares, and Maljaee, 2016). Although mechanical characterization of TRMs (Leone et al., 2017; Lignola et al., 2017), or the bond between TRM and masonry substrate (Ascione, De Felice, and De Santis, 2015; Razavizadeh et al., 2014) have been the subjects of several studies, the fiber-to-mortar bond 
response has not received the attention (Dalalbashi, Ghiassi, Oliveira, and Freitas, 2018a; Ghiassi et al., 2016). The fiber-to-mortar bond response of TRMs made of cementitious composites has been the subject of several studies, but this mechanism in case of lime-based TRMs that are usually used for strengthening of masonry structures is relatively unknown. The fundamental differences between the mechanical properties of lime-based and cementitious mortars indicates that a different bond behavior should be expected. Therefore, there is a clear need for understanding of this mechanism in lime-based TRMs and the parameters affecting that for fit-for-purpose design of TRMs, as well as, fully utilization of this strengthening system when application to masonry structures.

The age of mortar for performing pull-out tests (or any other mechanical characterization tests) on TRM composites seem to be a critical issue. Hydraulic lime-based mortars usually used in TRMs for application to masonry, and historical structures harden over prolonged periods. It means that probably the bond and mechanical properties of the TRM composite is also developed over longer periods, compared to the 30 days curing time commonly used for cementitious materials. In this study, to better understand the role of mortar age on the bond behavior of the fiber-to-mortar, pull-out tests are performed from 15 to 180 days of curing, and the results are compared and discussed.

\section{Experimental Program}

The experimental program consists of evaluating the role of mortar age on the pull-out response of single fibers embedded in lime-based mortars. For this puxpose, two commonly used fiber types (steel and glass) with their counterpar investigations.

\subsection{Materials}

Materials consisted of two commercial hydraulic lime-based mortars referred to as M1 and

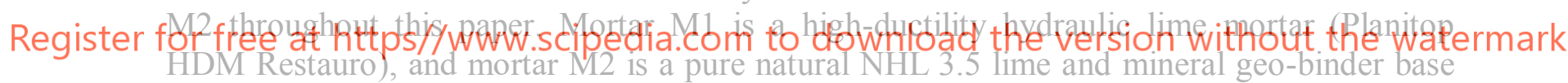
(GeoCalce).

The reinforcing materials are glass and steel fibers. The glass fiber is a woven biaxial fabric mesh (Mapegrid G220), and based on the technical datasheets, the elongation at breakage, modulus of elasticity, and tensile strength are $1.8 \%, 72 \mathrm{GPa}$, and of $45 \mathrm{kN} / \mathrm{m}$, respectively. The steel fiber is a unidirectional ultra-high tensile steel sheet (GeoSteel G600) and is made by twisting five individual wires together. The density and effective area of one cord (five wires) is equal to $670 \mathrm{~g} / \mathrm{m}^{2}$ and $0.538 \mathrm{~mm}^{2}$, respectively. Additionally, its tensile strength and elastic modulus are equal to $2800 \mathrm{MPa}$ and $190 \mathrm{GPa}$, respectively.

The fiber/mortar pairs are selected from the same provider in this study. It means that the glass fibers are used with the mortar M1 and the steel fibers with the mortar M2.

\subsection{Material Characterization Tests}

Mechanical characterization tests on mortar included compressive and flexural tests, according to ASTM C109 and EN 1015-11. The changes in the mechanical properties of mortar with curing age are evaluated by performing the tests at the ages of $14,28,60,90,180$ days. 
The compressive tests are performed on five cubics $\left(50 \times 50 \times 50 \mathrm{~mm}^{3}\right)$ specimens at each age with a Lloyd testing machine under force-controlled conditions at a rate of $2.5 \mathrm{~N} / \mathrm{s}$. A pair of Teflon sheets with a layer of oil in between is placed between the specimens and the compression plates to reduce friction near the boundaries (Figure 1a). The flexural tests are performed on five prismatic $\left(40 \times 40 \times 160 \mathrm{~mm}^{3}\right)$ specimens, at each age, following a threepoint bending test scheme (Figure $1 \mathrm{~b}$ ). The tests are performed with a Lloyd testing machine under force-controlled conditions at a rate of $10 \mathrm{~N} / \mathrm{s}$.
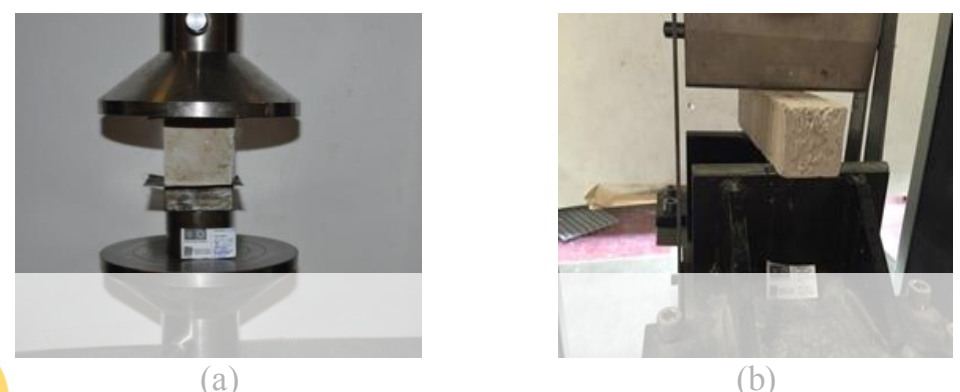

Figure 1. Mechanical characterization tests: (a) mortar compressive test; (b) mortar flexural test.

2.3 Pull-out Test

The single-sided pull-

al., 2018a) is used in thast

specimens consist of fib

Figure 2). The free leng

cross-sectional area of

procedure followed for the prenaration of the spe

et al., 2018a). The embedded lengths of steel and glass fibers are equal to 150 and $50 \mathrm{~mm}$,

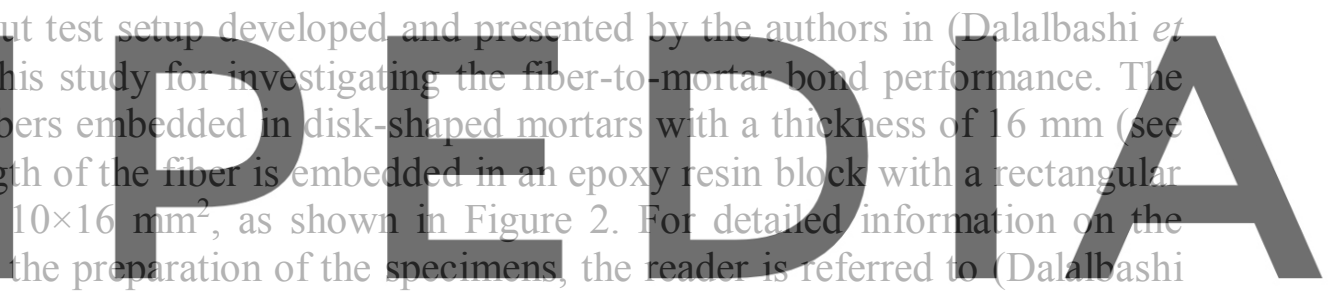

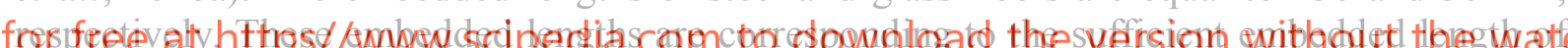

each composite system (Dalalbashi, Ghiassi, Oliveira, and Freitas, 2018b). The specimens are

demolded after 24 hours of preparation and are stored in the lab environmental conditions

$\left(20^{\circ} \mathrm{C}, 60 \% \mathrm{RH}\right)$ until the test day. Both glass and steel-based specimens are tested at the ages of $15,30,90$, and 180 days ,to evaluate the role of mortar age on the fiber-to-mortar bond behavior.

U-shape steel support is utilized for supporting the specimens (Figure 2). A mechanical clamp is used to grip the epoxy resin from the top. Also, two LVDTs with a $20 \mathrm{~mm}$ range and $2-\mu \mathrm{m}$ sensibility are located at the side and in front of the epoxy block, at the vicinity of the mortar edge, to record the slip. All the tests are carried out using a servo-hydraulic system with a maximum capacity of $25 \mathrm{kN}$ at a displacement rate of $1.0 \mathrm{~mm} / \mathrm{min}$.

\section{Experimental Results and Discussion}

\subsection{Material Properties}

Table 1 presents the changes of mortars' mechanical properties with age. Although both mortars show similar value for the maximum compressive strength $(8.31 \mathrm{MPa}$ for $\mathrm{M} 1$ and 
9.53 MPa for M2), the peak values are reached at different times. Mortar M2 shows the maximum gain of compressive strength in the first 30 days, and after that, a slight decrement of compressive strength is observed until 180 days. Meanwhile, mortar M1 reaches its peak compressive strength in 60 days, and after that, the changes in the compressive strength are negligible.

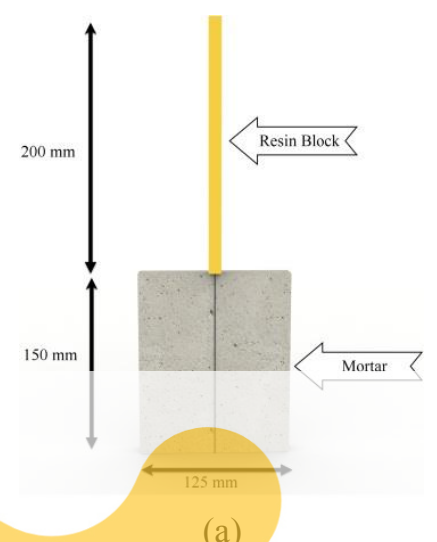

(a)

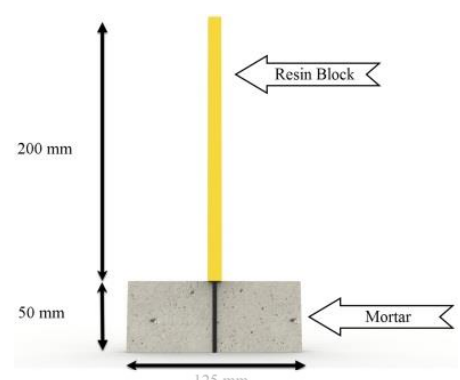

(b)

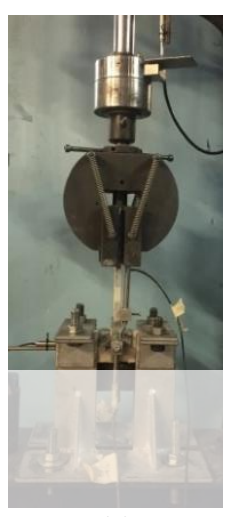

(c)

Figure 2. Details of pull-out specimens and test: (a) steel-based TRM; (b) glass-based TRM; (c) test setup.

Mortar M2 reaches its peak flexural strength in the first 30 days, but the flexural strength

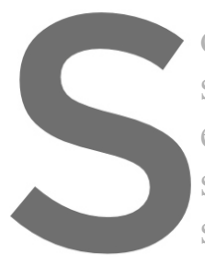
of mortar M1 increase strength of the mortar, an experimental pull-out c strength $(6.0 \mathrm{MPa})$, strength that is an indica
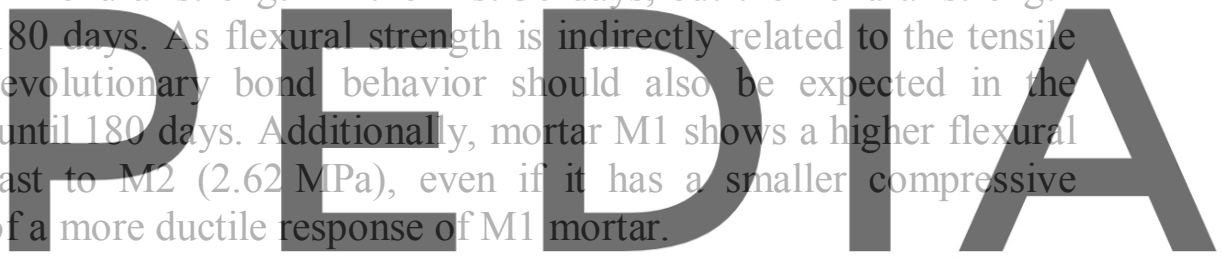

Table 1. Mortar mechanical properties with age.

Register for free at https//www.scipedia.com to download the version without the watermark

\begin{tabular}{ccccccc} 
Mortar & $\begin{array}{r}\text { Test } \\
{[\mathrm{MPa}]}\end{array}$ & 14 & 28 & 60 & 90 & 180 \\
\cline { 5 - 7 } M1 & $\begin{array}{c}\text { Compressive } \\
\text { strength }\end{array}$ & $5.91(8)$ & $7.07(9)$ & $8.31(11)$ & $7.84(4)$ & $7.46(10)$ \\
\hline M1 & $\begin{array}{c}\text { Flexural } \\
\text { strength }\end{array}$ & $4.03(3)$ & $4.71(7)$ & $5.10(3)$ & $4.66(8)$ & $6.0(10)$ \\
\hline M2 & $\begin{array}{c}\text { Compressive } \\
\text { strength }\end{array}$ & $8.76(7)$ & $9.53(10)$ & $8.81(12)$ & $8.89(5)$ & $7.48(5)$ \\
\hline M2 & $\begin{array}{c}\text { Flexural } \\
\text { strength }\end{array}$ & $1.79(12)$ & $2.54(9)$ & $2.09(7)$ & $2.33(9)$ & $2.62(13)$ \\
\hline
\end{tabular}

Coefficients of variation (\%) are provided in parentheses.

\subsection{Pull-out Response}

\subsubsection{Steel-based TRM composite}

Figure 3 and Table 2 present the evolution of the pull-out response of steel-based TRMs with time and the summary of the main characteristics of the pull-out curves of different ages. 
A typical three-stage of the bond behavior of the fiber-to-mortar (linear, nonlinear, and dynamic stage) is shown by the pull-out response of steel-based TRM at all ages. The linear elastic range terminates with the first debonding at the interface occurs that leads to a concave-downward shape in the pull-put curves (D'Antino, Carrozzi, Colombi, and Poggi, 2017). Once the peak load is reached, which is corresponding to the full debonding along the embedded length, the pull-out load is dropped, because the bond force is larger than the frictional force in this system $(\mathrm{Li}, \mathrm{Wu}$, and Chan, 1995). The pull-out curves, then, show a strain hardening behavior (forming a second peak load) and then a softening response until the end of the tests.

By comparing the average curves, a slight increase in the pull-out response can be observed in the first 30 days, followed by a slight decrease until 180 days. A possible explanation for this phenomenon is due to the changes in the mechanical properties of the mortar M2 that followed a very similar trend with time. Table 2 shows the bond properties of steel-based TRM. While the toughness follows a similar trend as the peak load (increases initially and then a decrease), the slip corresponding to the first peak load is almost constant. At the same time, the initial stiffness of the pull-out curves seems to be decreasing with time.
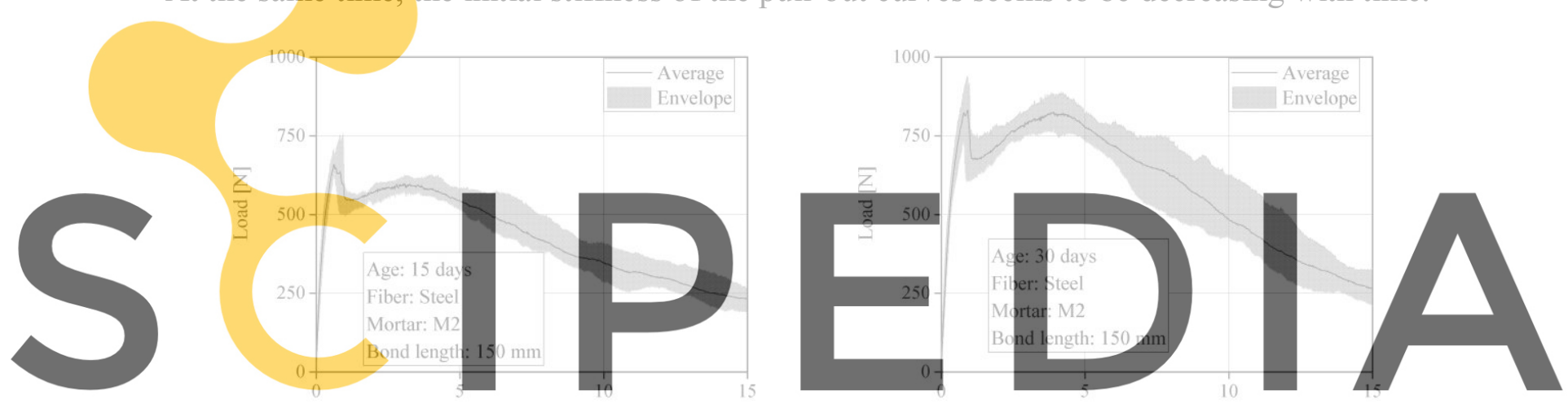

Slip $[\mathrm{mm}]$

Slip $[\mathrm{mm}]$

Register for free at https//ww'w.scipedia.com to download the versibn without the watermark

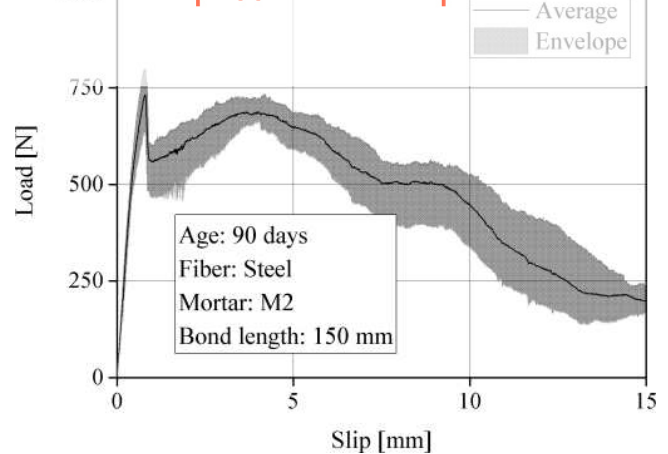

(c)

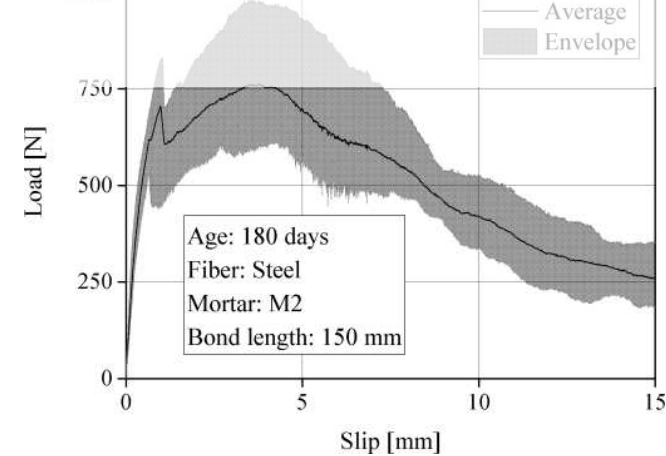

(d)

Figure 3. Envelope load-slip curves of steel-based TRM at different mortar ages: (a) 15 days; (b) 30 days; (c) 90 days; (d) 180 days . 
Table 2. Effect of mortar age on the pull-out response of steel-based TRMs.

\begin{tabular}{|c|c|c|c|c|c|c|}
\hline \multirow[t]{2}{*}{$\begin{array}{l}\text { Age } \\
\text { [days] }\end{array}$} & \multirow{2}{*}{$\begin{array}{c}\text { Slip } \\
\text { corresponding } \\
\text { to peak load } \\
{[\mathrm{mm}]}\end{array}$} & \multirow[t]{2}{*}{$\begin{array}{c}\text { Peak load } \\
{[\mathrm{N}]}\end{array}$} & \multicolumn{3}{|c|}{$\begin{array}{l}\text { Toughness at a crack opening of } \\
\text { [N.mm] }\end{array}$} & \multirow{2}{*}{$\begin{array}{c}\text { Initial } \\
\text { stiffness } \\
{[\mathrm{N} / \mathrm{mm}]}\end{array}$} \\
\hline & & & $1 \mathrm{~mm}$ & $4 \mathrm{~mm}$ & $8 \mathrm{~mm}$ & \\
\hline 15 & $0.8(16)$ & $711(7)$ & $511(8)$ & $2238(4)$ & $4236(5)$ & $1903(19)$ \\
\hline 30 & $0.9(9)$ & $872(9)$ & $599(10)$ & $2861(5)$ & $5745(6)$ & $2076(23)$ \\
\hline 90 & $0.8(3)$ & $741(9)$ & $474(8)$ & $2372(7)$ & $4747(7)$ & $1277(10)$ \\
\hline 180 & $0.9(16)$ & $731(17)$ & $476(16)$ & $2581(15)$ & $5143(17)$ & $1360(14)$ \\
\hline
\end{tabular}

Coefficients of variation (\%) are provided in parentheses.

\subsubsection{Glass-based TRM composite}

It can be observed that the pull-out response of the glass-based TRMs shows a significant change with time, as shown in Figure 4. At the mortar ages of 15 and 30 days, after complete debonding (at peak load), a descending trend in the pull-out force can be observed. In contrast, at the age of 90 and 180 days, the pull-out force increases after complete debonding, showing a slip hardening behavior. This behavior, again, is in-line with the observed changes in the mechanical properties of mortar M1. The flexural strength of mortar M1 continuously increased until 180 days, and therefore increasing bond strength is also expected to be

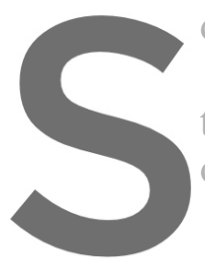
developed during this period.

The summary of the the peak load is relative of the pull-out curves increase with time until
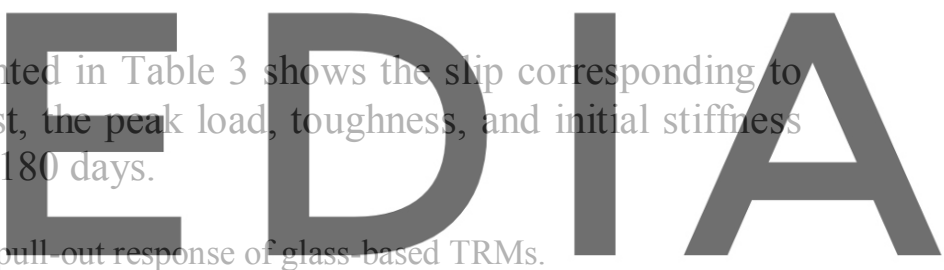

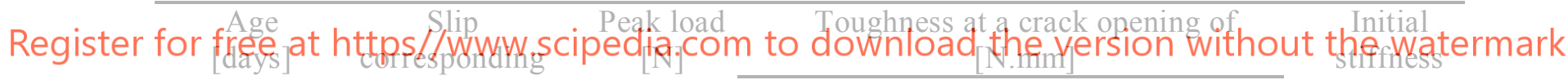

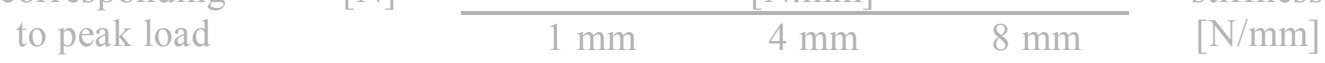
$[\mathrm{mmi}]$

\begin{tabular}{ccccccc}
\hline 15 & $2.6(12)$ & $285(10)$ & $154(11)$ & $914(10)$ & $1778(4)$ & $456(4)$ \\
\hline 30 & $1.9(31)$ & $251(30)$ & $156(18)$ & $805(24)$ & $1540(27)$ & $815(22)$ \\
\hline 90 & $2.3(13)$ & $379(16)$ & $227(9)$ & $1727(12)$ & $2476(16)$ & $858(22)$ \\
\hline 180 & $2.3(27)$ & $391(12)$ & $191(17)$ & $1252(3)$ & $2673(9)$ & $909(35)$ \\
\hline
\end{tabular}

Coefficients of variation (\%) are provided in parentheses. 


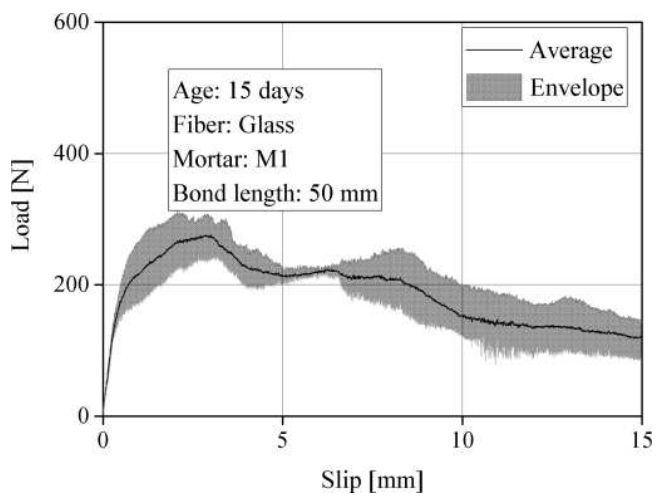

(a)

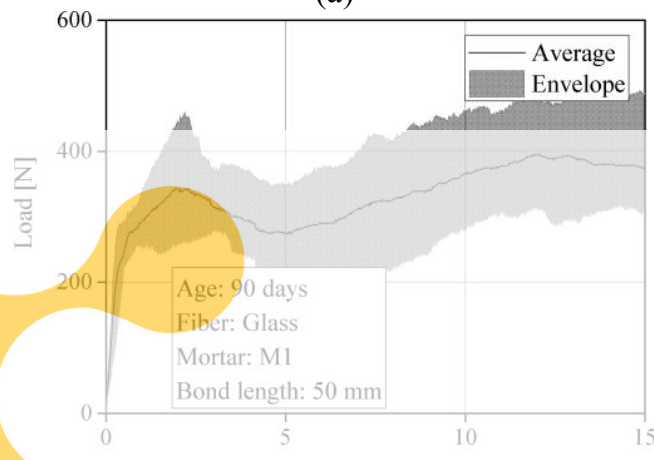

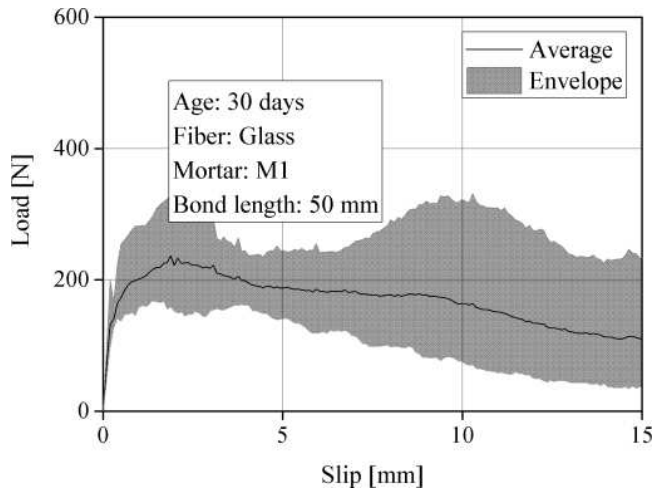

(b)
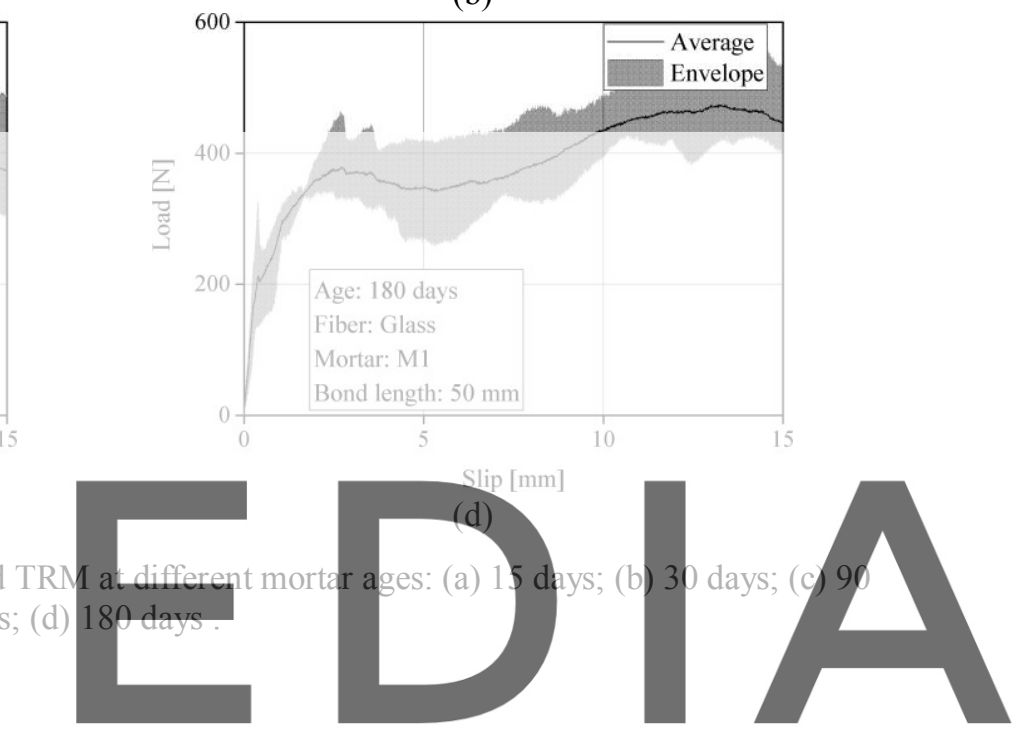

\section{Conclusions}

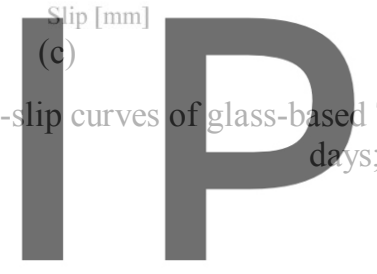

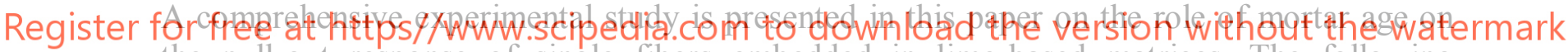
the pull-out response of single fibers embedded in lime-based matrices. The following conclusions can be drawn from the obtained experimental results:

- The results show the significant effect of mortar age on the bond response. In particular, it seems that the 30 days curing period that is usually used for cementitious mortars is not suitable for lime-based mortars.

- It is difficult to propose a generic curing time for performing the pull-out tests when lime-based mortar is used as the matrix. In one of the studied mortars, 60 days of curing seemed to be sufficient for obtaining realistic bond behavior, while in the other mortar 90 days is found to be the minimum required aging time.

- The changes of flexural strength of the mortar seemed to be a good indication of the changes in the bond behavior and are suggested to be considered in investigations for estimating the suitable curing age for evaluating the mechanical properties and bond response of these systems. 


\section{Acknowledgements}

This work was partly financed by FEDER funds through the Competitivity Factors Operational Programme (COMPETE) and by national funds through the Foundation for Science and Technology (FCT) within the scope of the project POCI-01-0145-FEDER-007633. The support to the first author through grant SFRH/BD/131282/2017 is acknowledged. Also, the authors would like to thank the Kerakoll Company for supplying the GeoCalce Fino mortar as well as GeoSteel G600 fibers.

\section{ORCID}

Ali Dalalbashi: https://orcid.org/0000-0003-0486-1433

Bahman Ghiassi: http://orcid.org/0000-0003-4212-8961

Daniel V. Oliveira: http://orcid.org/0000-0002-8547-3805

\section{References}

Ascione, L., De Felice, G. and De Santis, S. (2015). A qualification method for externally bonded Fibre Reinforced Cementitious Matrix (FRCM) strengthening systems. Composites Part B: Engineering, 78, 497506. doi: 10.1016/j.compositesb.2015.03.079

Carozzi, F. G. and Poggi, C. (2015). Mechanical properties and debonding strength of Fabric Reinforced Cementitious Matrix (FRCM) systems for masonry strengthening. Composites Part B: Engineering, 70, 215230. doi: 10.1016/j.compositesb.2014.10.056

D’Antino, T., Carrozzi, F. G., Colombi, P. and Poggi, C. (2017). A New Pull-Out Test to Study the Bond Behavior of Fiber Reinforced Cementitious Composites. Key Engineering Materials, 747, 258-265. doi: 10.4028/www.scientific.net/KEM.747.258

Dalalbashi, A., Ghiassi, B., Oliveira, D. V. and Freitas, A. (2018a). Effect of test setup on the fiber-to-mortar

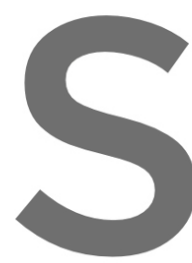
pullout response in Engineering, 143, 250

Dalalbashi, A., Ghiassi, composites: effect of ent doi: $10.1016 /$ j.compos
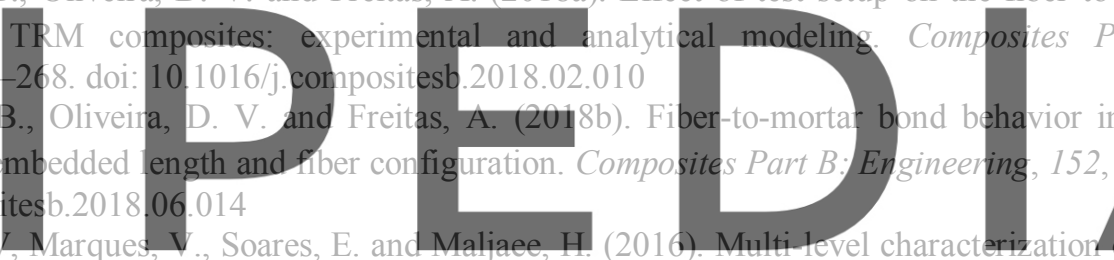
reinforced mortars for strengthening of masonry structures. Materials and Design, 110, 903-913. doi: fabric reinforced cementitious matrix: Tensile properties and bond performance on masonry substrate. Composites Part B. Engineering, 127. doi: 10.1016/j.compositesb.2017.06.028

Li, V. C., Wu, H. C. and Chan, Y. W. (1995). Interfacial property tailoring for pseudo strain- hardening cementitious composites. Adv Technol Des Fabr Compos Mater Struct Eng Appl Fract Mech, 14. doi: 10.1007/978-94-015-8563-7_18.

Lignola, G. P., Caggegi, C., Ceroni, F., De Santis, S., Krajewski, P., Lourenço, P. B. and Zuccarino, L. (2017). Performance assessment of basalt FRCM for retrofit applications on masonry. Composites Part B: Engineering, 128, 1-18. doi: 10.1016/j.compositesb.2017.05.003

Papanicolaou, C. G., Triantafillou, T. C., Papathanasiou, M. and Karlos, K. (2007). Textile-reinforced mortar (TRM) versus FRP as strengthening material of URM walls: in-plane cyclic loading. Materials and Structures, 40(10), 1081-1097. doi: 10.1617/s11527-006-9207-8

Razavizadeh, A., Ghiassi, B. and Oliveira, D. V. (2014). Bond behavior of SRG-strengthened masonry units: Testing and numerical modeling. Construction and Building Materials, 64, 387-397. doi: 10.1016/j.conbuildmat.2014.04.070 